\title{
Mental workload and its association with fatigue in operating room personnel of Hamadan hospitals, Iran, 2016
}

\author{
Motamedzade M, $\mathrm{PhD}^{1}$, Abbasinia M, MSc${ }^{2}$, Parvari R, $\mathrm{MSc}^{2}$, Oliaie M, MSc${ }^{2}$, Karimi S, BSc ${ }^{3}$, \\ Mohammadi $\mathrm{P}, \mathrm{MSc}^{2 *}$ \\ 1- Professor, Dept. of Ergonomics, School of Public Health, Hamadan University of Medical Sciences, Hamadan, Iran. 2- PhD \\ Student in Occupational Health, Dept. of Occupational Health, School of Public Health, Hamadan University of Medical \\ Sciences, Hamadan, Iran. 3-MSc Student in Occupational Health, Dept. of Occupational Health, School of Public Health, \\ Hamadan University of Medical Sciences, Hamadan, Iran.
}

Abstract

Received: May 2017, Accepted: July 2017

Background: Fatigue in the workers reduces the individual's resistance and eventually leads to the lower performance, increased errors and accidents. This study assessed the fatigue, mental workload and the correlation between them, in operating room personnel of Hamadan hospitals, Iran.

Materials and Methods: In a descriptive study, the mental workload and its association with fatigue in operating room personnel were investigated. Total of 188 cases including surgeons, nurses, operating room and anesthesia technicians participated in the study. Data were collected using demographic, fatigue and mental workload questionnaires, and were analyzed using SPSS software.

Results: The mean of overall mental workload was $74.3 \pm 10.8$. The results also showed that overall fatigue and its domains, including subjective fatigue, concentration, motivation and physical activity were $48.73 \%, 54.31 \%, 51.65 \%, 38.96 \%$ and $42.06 \%$, respectively. Among different domains of mental workload, performance $(\mathrm{r}=-0.380, \mathrm{P}<0.001)$ and frustration $(\mathrm{r}=0.222, \mathrm{P}=0.014)$ were significantly associated with overall fatigue. Between overall mental workload and overall fatigue, there was not a significant correlation $(r=0.029, \mathrm{P}=0.749)$. Among different dimensions of fatigue, only subjective fatigue was correlated with mental workload $(\mathrm{r}=0.255, \mathrm{P}=0.005)$.

Conclusions: Regarding the association of performance and the frustration with overall fatigue and the association of overall mental workload with subjective fatigue, it can be concluded that mental workload and fatigue may be correlated with each other. Therefore, any reduction in mental workload domains may lead to fatigue reduction in the operating room personnel.

Keywords: Workload, Fatigue, Operating Room, Personnel, Questionnaire

\section{Introduction}

Fatigue is defined as a temporary loss of energy and strength, resulting from hard or long time physical or mental work and usually results in performance decrement. This occurs when the body cannot provide enough energy to perform a task. The depletion of energy increases muscle fatigue to the point whereby physical or mental activity cannot be performed (1-3). Eventually, tired people may do their normal work procedures with error. Generally, fatigue may cause a feeling of contusion, decreased physical function, autonomic nervous system imbalance, and reduced work efficiency. Tired people are

\footnotetext{
* Corresponding author: Pejman Mohammadi, Dept. of Occupational Health, School of Public Health, Hamadan University of Medical Sciences, Hamadan, Iran.

E-mail: Pmohammadi64@gmail.com
} 
also more likely to choose risky behaviors such as taking shortcut routes to carry out their tasks (4-6).

Job dissatisfaction, mild mental disorders, lack of sleep and workload are mentioned in literature as fatigue risk factors in the job $(7,8)$. Higher workload, the existence of fatigue and inappropriate working time schedule, lead to lower efficiency and loss of memory, impaired thinking processes, irritability and reduced learning (9). For example, high levels of the workload in the laparoscopic task as a medical job have resulted in decreased performance (10). There are several ways to measure workload. A simple method to measure the workload is a subjective method. According to this method, if a person feels heavy workload so the workload is categorized as high (11). Although physiological measurements are more accurate, subjective methods are more practical (12). Multidimensional methods are the most common and accepted subjective methods to measure mental workload. National Aeronautics and Space Administration-Task Load Index (NASATLX) is a good multi-dimensional scale for measuring mental workload, very sensitive to changes in workload and also has a high level of diagnosticity (13-15). There is not a direct way to measure fatigue. However, fatigue can be measured from its consequences and symptoms or from the physiological or psychological indications associated with the symptoms of fatigue (16).

Healthcare professions are of high sensitivity in nature due to concerns around patient's safety in the hospitals, increasing probability of human errors in tired personnel as well as and weak psychomotor and cognitive performance. (17, 18). Moreover, the increased workload can increase job pressures and cause difficulties in the decision making process in the healthcare personnel. Among the healthcare personnel, operating room personnel are subjected to high levels of mental workload, because they are always taking important decisions that are related to patient life and safety $(19,20)$.

To our knowledge, there was not any published study about the association between mental workload and fatigue in operating room personnel of hospitals. Therefore, we decided to study fatigue and mental workload prevalence in the operating room personnel and the association between mental workload and fatigue. We hope to provide a scientific basis for management measures in order to reduce the mental workload and consequently the fatigue in the personnel and eventually increase the patient safety in the operating room.

\section{Materials and Methods}

In a descriptive study, mental workload and its association with fatigue in operating room personnel of Besat, Fatemieh, Tamin ejtemaei, Farshchian and Shahid Beheshti hospitals, Hamadan, Iran, were investigated in 2016.

Based on census method, 188 cases of operating room personnel including surgeons, nurses, operating room and anesthesia technicians who would like to participate in the research voluntarily were recruited. All of the participants were assured that their information will remain confidential to the researcher. Moreover, participants were not asked to enter their names in the demographic questionnaire. Demographic characteristics of the participants include age, gender, job, marriage status, work experience, educational degree, monthly work-hours, type of shift work (fixed night shift, fixed morning shift, fixed evening shift, and rotating shift work), working in multiple hospitals, expertise and type of employment were collected using a demographic characteristics questionnaire.

CIS20R questionnaire was used to assess fatigue (21). Reliability and validity of CIS20R questionnaire were evaluated by Habib and colleagues for emergency service personnel. They obtained reliability of 0.86 for this questionnaire (22). CIS20R contains 20 
questions related to 4 dimensions of fatigue including subjective fatigue, concentration, motivation and physical activity levels. Each of these dimensions has a response boxes ranging from 1 to 6 and the sum of this 4 domain score indicates overall fatigue severity. In this questionnaire, the more overall fatigue score was interpreted as the more overall fatigue severity (23).

Mental workload was assessed using NASATLX (24). The validity of the Persian version of this scale has been confirmed by Mohammadi et al. $(\alpha=0.847)$ (9). The NASA-TLX uses six dimensions to assess workload including mental demand, physical demand, temporal demand, performance, effort, and frustration. This multidimensional index estimates workload during work or immediately after work (25-27).

After giving a brief description to the main objectives of the study, questionnaires were completed by participants.

Statistical analysis was performed using SPSS software (version 16.0, SPSS Inc., Chicago, IL, USA). To find the correlation between parameters, statistical tests of Pearson correlation, analysis of variance (ANOVA) and paired t-test were used. The significance level was set at 0.05 .

Table 1: Ratings for overall mental workload and its subscales (domains) in operating room personnel

\begin{tabular}{ccccc}
\hline NASA-TLX Subscales & Mean & SD & MIN & MAX \\
\hline Mental demand & 76.4 & 19.5 & 20 & 100 \\
\hline Physical demand & 77.1 & 19.0 & 10 & 100 \\
\hline Temporal demand & 76.0 & 17.1 & 27 & 100 \\
\hline Effort & 76.8 & 15.8 & 23 & 100 \\
\hline Performance & 75.9 & 17.1 & 20 & 100 \\
\hline Frustration & 63.8 & 22.3 & 10 & 100 \\
\hline Overall workload & 74.3 & 10.8 & 41.2 & 100 \\
\hline
\end{tabular}

NASA-TLX: National Aeronautics and Space Administration-Task Load Index; SD: Standard deviation;

\section{Results}

Participants were surgeons (15.6\%), nurses $(22.1 \%)$, operating room technicians $(22.1 \%)$ and anesthesia technicians (40.2\%). In this study, 102 were women and 86 were men. Among the participants, 67 were single and 121 were married. The mean age of subjects $( \pm$ standard deviation) was $32.6 \pm 7.5$ years, minimum and maximum age of participants was 20 and 53 years, respectively. The mean work experience of subjects was $8.78 \pm 6.61$ years; the minimum and maximum were 1 and 32 years respectively. The mean monthly work hours of participants were $218 \pm 81.7$ hours, minimum and maximum monthly work hours of participants was 70 and 400, respectively. Participants' educational degrees were bachelor of science (BSc, 52.7\%), master of science (MSc, 11.2\%), specialist (11.2\%), professor $(6.9 \%)$, general practitioner $(1.6 \%)$, associate degree $(15.4 \%)$ and diploma (1\%). The mean of the overall mental workload rating of participants was $74.3 \pm 10.8$. The average rating for the subscales of mental workload stated by participants is shown in table 1 .

The mean rating for fatigue and its subscales stated by participants is listed in table 2 . 
Table 2: Mean rating for fatigue and its subscales in operating room personnel

\begin{tabular}{cccccc}
\hline Fatigue domains & Rating range & Mean & SD & Min & Max \\
\hline Subjective fatigue & $8-48$ & 26.10 & 7.02 & 9 & 48 \\
\hline Concentration & $5-30$ & 15.30 & 3.78 & 5 & 25 \\
\hline Motivation & $4-24$ & 9.43 & 2.63 & 4 & 18 \\
\hline Physical activity levels & $3-18$ & 7.53 & 2.51 & 3 & 16 \\
\hline Overall fatigue & $20-120$ & 58.40 & 11.90 & 28 & 97 \\
\hline
\end{tabular}

SD: Standard deviation

Relationships between studied demographic variables and mental workload and overall fatigue were analyzed with Pearson correlation, analysis of variance (ANOVA) and paired t-test (Tables 3 and 4).

Table 3: Correlation of demographic variables with the mental workload and overall fatigue

\begin{tabular}{ccccc}
\hline \multirow{2}{*}{$\begin{array}{c}\text { Demographic } \\
\text { Characteristic }\end{array}$} & \multicolumn{2}{c}{ Mental workload } & \multicolumn{2}{c}{ Overall fatigue } \\
\cline { 2 - 5 } & $\mathbf{P}$ & $\mathbf{R}^{\mathbf{2}}$ & $\mathbf{P}$ & $\mathbf{R}^{\mathbf{2}}$ \\
\hline Age & 0.254 & 0.007 & 0.731 & 0.001 \\
\hline Work experience & 0.080 & 0.016 & 0.525 & 0.002 \\
\hline Monthly work-hours & 0.210 & 0.008 & 0.022 & 0.028 \\
\hline
\end{tabular}

The work shift had a significant effect on overall fatigue. Since only one person was in the night shift work, there was not the feasibility of LSTtest. So, pairwise comparisons were not conducted. The educational degree was significantly related to mental workload. Pairwise comparisons showed that mental workload in associate degree group was more than $\mathrm{BSc}$ and professor groups $(\mathrm{P}=0.032$ and $\mathrm{P}$ $=0.019$, respectively), in BSc group was lower than MSc and specialist groups $(\mathrm{P}=0.039$ and $\mathrm{P}$
$=0.020$, respectively), and in MSc and specialist groups was more than professor group $(\mathrm{P}=$ 0.019 and $\mathrm{P}=0.012$, respectively).

Pearson correlation test showed that among the different domains of mental workload, only performance and frustration had a significant correlation with overall fatigue (Table 5). Between other domains of mental workload and overall fatigue, as well as between mental workload and overall fatigue there was not any significant correlation (Table 5).

Table 4: Association of demographic variables with the mental workload and overall fatigue

\begin{tabular}{ccccc}
\hline \multirow{2}{*}{ Demographic Characteristic } & \multicolumn{2}{c}{ Mental workload } & \multicolumn{2}{c}{ Overall fatigue } \\
\cline { 2 - 5 } & $\mathbf{P}$ & $\mathbf{t}$ or $\mathbf{F}$ & $\mathbf{P}$ & t or $\mathbf{F}$ \\
\hline Gender & 0.897 & 1.225 & 0.646 & $-2.111 \square$ \\
\hline Marital status & 0.931 & -1.426 & 0.459 & -1.481 \\
\hline Working in multiple hospitals & 0.833 & -1.936 & 0.203 & 0.417 \\
\hline Job & 0.891 & $0.207^{\dagger}$ & 0.613 & $0.604^{\dagger}$ \\
\hline Work shift & 0.458 & $0.785^{\dagger}$ & 0.018 & $4.131^{\dagger}$ \\
\hline Educational degree & 0.021 & $2.551^{\dagger}$ & 0.417 & $1.015^{\dagger}$ \\
\hline Type of employment & 0.117 & $1.991^{\dagger}$ & 0.912 & $0.176^{\dagger}$ \\
\hline
\end{tabular}

t-value in t-test

${ }^{\dagger} \mathrm{F}$ - value in analysis of variance (ANOVA) 
Table 5: Statistical test results for correlation between mental workload and fatigue in the operating room personnel

\begin{tabular}{|c|c|c|c|c|c|c|}
\hline \multirow{2}{*}{$\begin{array}{c}\text { Mental } \\
\text { workload } \\
\text { domains }\end{array}$} & & \multicolumn{5}{|c|}{ Fatigue domains } \\
\hline & & Subjective fatigue & Concentration & Motivation & Physical activity levels & Overall fatigue \\
\hline \multirow{2}{*}{$\begin{array}{l}\text { Mental } \\
\text { demand }\end{array}$} & $\mathrm{r}$ & 0.087 & -0.020 & -0.093 & -0.163 & -0.010 \\
\hline & $\mathrm{P}$ & 0.233 & 0.783 & 0.206 & 0.025 & 0.893 \\
\hline \multirow{2}{*}{$\begin{array}{c}\text { Physical } \\
\text { demand }\end{array}$} & $\mathrm{r}$ & 0.223 & -0.097 & -0.021 & -0.256 & 0.042 \\
\hline & $\mathrm{P}$ & 0.002 & 0.183 & 0.775 & $<0.001$ & 0.569 \\
\hline \multirow{2}{*}{$\begin{array}{c}\text { Temporal } \\
\text { demand }\end{array}$} & $\mathrm{r}$ & 0.241 & -0.015 & -0.044 & 0.048 & 0.118 \\
\hline & $\mathrm{P}$ & 0.001 & 0.833 & 0.550 & 0.509 & 0.107 \\
\hline \multirow{2}{*}{ Effort } & $\mathrm{r}$ & 0.094 & -0.028 & -0.122 & -0.180 & -0.019 \\
\hline & $\mathrm{P}$ & 0.201 & 0.701 & 0.096 & 0.013 & 0.799 \\
\hline \multirow{2}{*}{ Performance } & $\mathrm{r}$ & -0.183 & -0.342 & -0.330 & -0.311 & -0.357 \\
\hline & $\mathrm{P}$ & 0.012 & $<0.001$ & $<0.001$ & $<0.001$ & $<0.001$ \\
\hline \multirow{2}{*}{ Frustration } & $\mathrm{r}$ & 0.205 & 0.046 & 0.117 & 0.183 & 0.202 \\
\hline & $\mathrm{P}$ & 0.005 & 0.531 & 0.108 & 0.012 & 0.006 \\
\hline \multirow{2}{*}{$\begin{array}{c}\text { Overall } \\
\text { workload }\end{array}$} & $\mathrm{r}$ & 0.200 & -0.119 & -0.121 & -0.199 & 0.011 \\
\hline & $\mathrm{P}$ & 0.006 & 0.103 & 0.098 & 0.006 & 0.880 \\
\hline
\end{tabular}

\section{Discussion}

This study showed that the mean rating of mental workload in operating room personnel was 74.3 ( $\mathrm{SD}=10.8$ ). The maximum and minimum ratings were belonged to physical demand $($ mean $=77.1 \pm 19.0)$ and frustration $(63.8 \pm 22.3)$, respectively.

In a study conducted to evaluate the mental workload and its affecting factors among the nurses of Kashan, Iran (Sarsangi et al.), it has been reported that the maximum rating belongs to effort and minimum rating belongs to frustration. We found that the minimum rating belongs to frustration in both studies. The mean rating of $69.5 \pm 15.7$ for mental workload has been reported by Sarsangi et al. that is lower than the mean of workload rating in our study. This comparison shows the importance of mental workload in operating room personnel (27).

Although the overall mental workload was significantly correlated only with work experience, certain demographic characteristics were associated with some of the mental workload subscales. Demographic characteristics, such as age, were statistically correlated with mental demand $(\mathrm{P}=0.005)$, work experience with performance $(\mathrm{P}=0.045)$ and monthly work-hours with effort $(\mathrm{P}=0.004)$. These findings mean that when age, working history or monthly work-hours increase, the mental workload experienced by personnel also increases. Although we did not find a significant association between gender and mental workload $(\mathrm{P}=0.883)$, physical demand and frustration domains of mental workload were statistically correlated with gender. So, we find that women feel greater physical workload than men. As well as gender, we did not find a significant association between marital status and mental workload $(\mathrm{P}=0.883)$, but mental demand and frustration domains of mental workload were statistically correlated with marital status, so the ratings for both of these domains were higher in married than singles. Although the job (surgeons, nurses, operating room and anesthesia technicians) was not significantly correlated with mental workload and its domains $(\mathrm{P}>0.050)$, the mental work in surgeons was higher than other jobs. 
The mean rating of overall mental workload in this study (74.3) was less than the mean rating obtained in the study of mental workload among the nurses of intensive care unit (82.3) and was higher than the mean rating obtained among the nurses of the orthopedic unit (63.5) in Malekpour study (28). The findings of Malekpour study show that mental workload is different in nurses of different units, but this difference was not found in different jobs in our study. The overall mental workload in this study was also more than that of has been reported in intensive care unit (ICU) nurses (71.4) (29). This finding shows the importance of mental workload in operating room personnel.

We did not find a significant association between shift work and mental workload $(\mathrm{P}=$ 0.783 ), which can be due to a mismatch between the number of samples in two working groups of day shift $(\mathrm{n}=18)$ and night shift $(\mathrm{n}=104)$ workers. Unlike this study, Sarsangi et al. has found a significant association between mental workload and age and type of work shift. Here, we can say again that this can be due to the mismatch between the number of samples in groups and Small sample size. But our study is consistent with Sarangis' report, showing that the mental workload has a significant correlation with work experience (27).

Another study by Habibie et al. has found that overall fatigue, subjective fatigue, concentration, motivation, and physical activity levels in emergency service personnel were $44.44 \%$, $49.40 \%, 45.40 \%, 38.75 \%$, and $37.22 \%$, respectively (22). Compared to Habibie's results (22), we can say that overall fatigue and its domains are more severe in operating room personnel than emergency service personnel. Moreover, the severity of fatigue domains in our study were higher than that of has been reported in workers exposed to jute dust, wood dust, chemicals and office workers (30). These results show the importance of fatigue in operating room personnel.
In this study, gender was not significantly correlated with overall fatigue but Raftopoulos et al. reported that fatigue prevalence in female nurses $(93 \%)$ is more than males $(87.5 \%)$ (31). This inconsistency in results may be due to different sample sizes in two studies.

Statistical test results showed that only performance and frustration have a significant inverse correlation with overall fatigue. This means that feeling lower fatigue rate is inversely proportional to a better performance. A similar correlation was also found between performance and concentration, and motivation and physical activity levels. These results of our study are consistent with barker et al. findings that have assessed fatigue in nurses (32). Small sample size especially the low number of surgeons was one of the drawbacks of our study. We suggest that other studies with a larger sample size should address the mental workload and fatigue as well as human errors resulting from higher mental workload and fatigue. Such studies will be useful to policy-makers of healthcare system to improve the work time scheduling, work shifts and the maximum number of surgeries that personnel can take part in.

\section{Conclusion}

In general, the results of this study showed that the mental workload in the operating room personnel is high. These personnel also feel fatigue to some degrees. By examining the different domains of fatigue it was observed that the mental workload is significantly correlated with mental fatigue. It can be concluded that mental workload may be correlated with fatigue and reducing the mental workload in operating room personnel may reduce fatigue.

\section{Acknowledgments}

The study was funded by the vice-chancellor for research and technology, Hamadan University of Medical Sciences (No. 9304242115). We would 
like to thank this university for cooperation and financial support. We also would like to thank the participants of this study.

Conflict of interest: None declared.

\section{References}

1. Hartzler BM. Fatigue on the flight deck: the consequences of sleep loss and the benefits of napping. Accid Anal Prev 2014; 62:309-18.

2. Dawson D, Cleggett C, Thompson K, Thomas MJ. Fatigue proofing: the role of protective behaviours in mediating fatigue-related risk in a defence aviation environment. Accid Anal Prev 2015; 99(Pt B):465-8.

3. Gander PH, Mulrine HM, van den Berg MJ, Smith AA, Signal TL, Wu LJ, et al. Pilot fatigue: relationships with departure and arrival times, flight duration, and direction. Aviat Space Environ Med 2014; 85(8):833-40.

4. Omidvari M. Examining the workplace heat effects on the workers precocious fatigue and their reduction of efficacy in Behshar Oil Refinery Company [MSc thesis]. Tehran: Tarbiat Modares University; 1995.

5. Amundsen AH, Sagberg F. Hours of service regulations and the risk of fatigue-and sleeprelated road accidents. A literature review. Swedish: National Road Administration, Institute of Transport Economics; 2003 May. 34 p. Rport No.:659/2003.

6. Owens JA. Sleep loss and fatigue in healthcare professionals. J Perinat Neonatal Nurs 2007; 21(2):92-100.

7. de Fatima Marinho de Souza M, Messing K, Menezes PR, Cho HJ. Chronic fatigue among bank workers in Brazil. Occup Med (Lond) 2002; 52(4):187-94.

8. Sasaki T, Iwasaki K, Mori I, Hisanaga N, Shibata E. Overtime, job stressors, sleep/rest, and fatigue of Japanese workers in a company. Ind Health 2007; 45(2):237-46.

9. Mohammadi M, Mazloumi A, Nasl Saraji J, Zeraati $\mathrm{H}$. Designing questionnaire of assessing mental workload and determine its validity and reliability among ICUs nurses in one of the TUMS's hospitals. Journal of School of Public Health and Institute of Public Health Research. 2013; 11(2):87-96.

10. Yurko YY, Scerbo MW, Prabhu AS, Acker CE, Stefanidis D. Higher mental workload is associated with poorer laparoscopic performance as measured by the NASA-TLX tool. Simul Healthc 2010; 5(5):267-71.

11. Johanssen G, Moray N, Pew R, Rasmussen J, Sanders A, Wickens C. Final report of experimental psychology group. In: Moray $\mathrm{N}$, editor. Mental workload. $1^{\text {st }}$ ed. New York City, United States: Springer Publishing; 1979. P. 10114.

12. Tattersall AJ, Foord PS. An experimental evaluation of instantaneous self-assessment as a measure of workload. Ergonomics 1996; 39(5):740-8.

13. Yeh YY, Wickens ChD. Dissociation of performance and subjective measures of workload. Hum Factors 1988; 30(1):111-20.

14. Byers JC, Bittner AC, Hill SG. Traditional and raw task load index (TLX) correlations: Are paired comparisons necessary? In: Mital A, editor. Advances in industrial ergonomics and safety I. $1^{\text {st }}$ ed. Abingdon-on-Thames, United Kingdom: Routledge, Taylor \& Francis; 1989:481-5.

15. Hill SG, Iavecchia HP, Byers JC, Bittner AC, Zaklade AL, Christ RE. Comparison of four subjective workload rating scales. Hum Factors 1992; 34(4):429-39.

16. Saito K. Measurement of fatigue in industries. Ind Health 1999; 37(2):134-42.

17. Sinha A, Singh A, Tewari A. The fatigued anesthesiologist: A threat to patient safety? J Anaesthesiol Clin Pharmacol 2013; 29(2):151-9.

18. Kurmann A, Tschan F, Semmer NK, Seelandt J, Candinas D, Beldi G. Human factors in the operating room - the surgeon's view. Trends in Anaesthesia and Critical Care 2012; 2(5):224-7.

19. Gurses AP, Carayon P. Performance obstacles of intensive care nurses. Nurs Res 2007; 56(3):18594.

20. Saremi M, Fallah MR. Subjective fatigue and medical errors among nurses in an educational hospital. Iran Occupational Health 2013; 10(4):18.

21. Vercoulen JH, Swanink CM, Fennis JF, Galama JM, van der Meer JW, Bleijenberg G. Dimensional assessment of chronic fatigue syndrome. J Psychosom Res 1994; 38(5):383-92.

22. Habibi E, Parvari R, Khodarahmi B, Dehghan HA, Hosseini M, Esmaili H. Assessment of the relationship between work schedule and fatigue among the emergency personnel of Isfahan, Iran using the check list individual strength standard method. Journal of Health System Research 2011; 7(6):1288-97. 
23. Makowiec-Dabrowska T, Koszada-Włodarczyk W. The CIS20R questionnaire and its suitability for prolonged fatigue studies. Med Pr 2005; 57(4):335-45.

24. Hart SG, Staveland LE. Development of NASATLX (Task Load Index): results of empirical and theoretical research. Advances in Psychology 1988; 52:139-83.

25. Gawron VJ. Human performance measures handbook. Mahwah, New Jersey London, United States: Lea Lawrence Erlbaum Associates; 2000. P.110-1.

26. Hart SG. NASA-task load index (NASA-TLX); 20 years later. Proceedings of the Human Factors and Ergonomics Society 50 ${ }^{\text {th }}$ Annual Meeting; 2006 ; Santa Monica: Human Factors and Ergonomics Society; 2006. P.904-8.

27. Sarsangi V, Saberi HR, Hannani M, Honarjoo F, Salim Abadi M, Goroohi M, et al. Mental workload and its affected factors among nurses in Kashan province during 2014. Journal of Rafsanjan University of Medical Sciences 2015; 14(1):25-36.

28. Malekpour F, Mohammadian Y, Malekpour AR,
Mohammadpour Y, Sheikh Ahmadi A, Shakarami A. Assessment of mental workload in nursing by using NASA-TLX. Journal of Urmia Nursing And Midwifery Faculty 2014; 11(11):892-899.

29. Hoonakker P, Carayon P, Gurses A, Brown R, McGuire K, Khunlertkit A, et al. Measuring workload of ICU nurses with a questionnaire survey: the NASA Task Load Index (TLX). IIE Trans Healthc Syst Eng 2011; 1(2):131-43.

30. Cordoneanu C, Grinea I, Branisteanu R, Bohosievici M, Cazuc V. Fatigue at workers exposed to jute dust, wood dust, chemicals and office workers. The Journal of Preventive Medicine 2004; 12(1-2):46-58.

31. Raftopoulos V, Charalambous A, Talias M. The factors associated with the burnout syndrome and fatigue in Cypriot nurses: a census report. BMC Public Health 2012; 12:457.

32. Barker LM, Nussbaum MA. Fatigue, performance and the work environment: a survey of registered nurses. J Adv Nurs 2011; 67(6):1370-82. 